\title{
"INTRÉPIDA CAPITAL DE PROVINCIA": UN DRAMA DE IDENTIDAD
}

\author{
Ivonne Robles Mohs
}

\begin{abstract}
RESUMEN
En "Intrépida capital de provincia", la variedad métrica, la acentuación múltiple, el encabalgamiento y la rima ponen de relieve la integración de las partes y de la variedad, es decir, de una conjunción, el poema, que se manifiesta como una larga tirada de versos, sin fragmentación. No obstante, la disposición de la rima traba, también, un significativo cruce de voces, de interrogantes: el tiempo, la agresividad, la persona.
\end{abstract}

\begin{abstract}
In "Intrépida capital de provincia", metric variety, multiple accentuation, enjambment and rhyme, bring out the integration of parts and variety, that is, of a union, the poem, which manifests itself as a long series of verses without fragmentation. Nevertheless, the disposition of rhyme also binds a meaningful crossing of voices, of questions: time, aggressiveness, person.
\end{abstract}

1. El poema

El texto, objeto de esta lectura, pertenece al poemario Cronista del presente, cuyo autor es Mario Ángel Marrodán, escritor español.

\section{Intrépida capital de provincia}

Te palpo desde dentro, ciudad donde naciera.

Al deambular por la belleza doliente de tus calles

con la urbana sumisión, me aniquilas.

Los exteriores municipales dan carácter

a sus tinieblas industriales. En tu ámbito me hiciste

y forjaste mi trabajo como una mercancía sugestiva

de hijo local de una ambiciosa plaza

que a golpes de riqueza se poblara.

Es el letargo de una ciudad cualquiera

que conozco y que habito, huera y ruda, 
mustia y nociva, protervamente renegada.

La orgía publicitaria nos deslumbra

tras esos lujosos matices de una urbe

crepuscular. A su tenaz arquitectura, al tráfico

hoy lleno de emigrados, me rindo taciturno

a sus pies y denuncio el ultraje de mi Bilbao explotador.

\section{La versificación}

\subsection{La variedad métrica y la acentuación múltiple}

Evidentemente, los dieciséis versos que constituyen el poema son de arte mayor, o sea, de más de ocho sílabas. Sin embargo, este conjunto de versos largos configura un rico y variado sistema métrico por medio de la combinación heterogénea del número de sílabas. Al considerar tanto las respectivas sinalefas en los versos oxítonos y en los versos paroxítono y proparoxítono, como las correspondientes licencias de disminución o de aumento en los versos esdrújulo y agudo, es claro que el poema conjuga versos pares e impares de once, doce, catorce, quince, dieciséis y dieciocho sílabas, con lo cual acentúa una integración, un encuentro y un diálogo de la diversidad métrica tonal.

\subsection{El encabalgamiento y la rima}

A excepción del primero, todos los demás versos establecen una conexión de unos con otros mediante el respectivo encabalgamiento.

Empero, el primer verso (naciera) se asocia por rima consonante con el noveno (cualquiera) y esta equivalencia de final de verso, exterior, se relaciona, también, con una equivalencia interior, por rima asonante con el quinto verso (tinieblas). Los dos casos representan, entonces, otra forma de encabalgamiento, de integración de las partes y de la variedad; en suma, de una conjunción, el poema, que se manifiesta como una larga tirada de versos, sin fragmentación.

Esta disposición de la rima exterior y de la interior traba, en forma de triángulo, un significativo cruce de voces, de tres interrogantes: el tiempo, la agresividad, la persona (Cros 1986: 254):

Te palpo desde dentro, ciudad donde naciera.

$\mathrm{Al}$ deambular por la belleza doliente de tus calles

con la urbana sumisión, me aniquilas.

Los exteriores municipales dan carácter

a sus tinie industriales. En tu ámbito me hiciste

y forjaste mi trałajo como una mercancía sugestiva

de hijo local de una ambiciosa plaza

que a golpes de riqueza se poblara.

Es el letargo de una ciudad cualqtidra.

Resulta insoslayable destacar que las cifras 1, 5, 9, donde concurren los dos lados del triángulo, representan el principio, el medio y el fin de la serie de los primeros números. Simbólicamente, el 1 es el lugar del ser, origen y fin de todas las cosas, y sobre todo es "symbole de l'homme debout: seul être vivant jouissant de cette faculté, au point que certains anthropologues 
font de la verticalité un signe distinctif de l'homme, plus radical encore que la raison" (Chevalier y Gheerbrant 1995: 984). El 5, dentro de su vasta expresión emblemática, comporta la del centro y el 9, en su complejidad, anuncia "à la fois une fin et un recommencement, c'est-à-dire une transposition sur un nouveau plan(...). II exprime la fin d'un cycle, l'achèvement d'une course, la fermeture de la boucle" (Chevalier y Gheerbrant 1995: 665).

\section{La situación de la comunicación}

El hablante, como sujeto, se asume en su presente (palpo, conozco, habito, me rindo, denuncio) y en su pasado (naciera); además, los posesivos de la primera persona (mi trabajo, mi Bilbao) y la reiteración del pronombre personal (me aniquilas, me hiciste, me rindo) ponen de relieve la importancia de la proyección del yo en esta poesía, pero sus relaciones consigo mismo son tan complejas como las que sostiene con su(s) destinatario(s).

De acuerdo con el Diccionario de la Lengua Española, el pretérito imperfecto es el tiempo que indica haber sido presente de la acción del verbo, coincidiendo con otra acción ya pasada (1992: 1664), y el modo subjuntivo es el que expresa la acción del verbo con significación de duda, posibilidad o deseo (1992: 1386).

En el poema, el yo marca tanto la coincidencia de las dos significativas acciones pretéritas como la consecuente indeterminación anímica con el empleo del sincretismo yo/él, propio de la primera y de la tercera personas del singular, en el pretérito imperfecto del subjuntivo (naciera).

Naciera o el pasado, señala la identidad del yo como una consubstancialidad, puesto que su salida del vientre materno coincide con la despersonalización que le confiere una сіиdad cualquiera; es decir, el nacimiento o la expulsión del vientre materno es correlativo a la inclusión en tu ámbito, el vientre del mundo de la explotación de los metales, del mercado y del comercio.

En su compleja consubstancialidad, el yo es, a la vez,

un hombre: (naciera, palpo, conozco, habito, me rindo, denuncio) y una mercancía, un metal: (En tu ámbito me hicistel y forjaste mi trabajo como una mercancía sugestival de hijo local de una ambiciosa plazal que a golpes de riqueza se poblaral (...) mi Bilbao explotador).

La ciudad cualquiera lo fabrica, le da forma de objeto; así como explota la riqueza de las minas e industrializa sus metales, los convierte en mercancías y los comercia, esta ciudad proyecta ese espíritu mercantilista en el hablante: lo metaliza, lo explota, lo hace mercancía y exhibe su rentabilidad; es objeto de cambio monetario, de comercio, al igual que los metales, tiene precio.

En este proceso de despersonalización, el yo aparece despojado de su linaje humano, desvinculado de toda consanguinidad, y, por lo tanto, como descendiente de un linaje económico, urbano, ávido de dinero y fundado por los encuentros violentos y por la explotación.

Es claro, entonces, que el hablante recurre al sincretismo yo/él (naciera) para captarse mejor y para describir ampliamente la aniquilación que ejerce una ciudad cualquiera. Este juego de perspectivas, de desdoblamiento, constituye, pues, un indicio de cómo el hablante repudia y denuncia esa consubstancialidad: con la superposición yo/él precisa, en el pasado, su alienación. Pero, también, con la reunión de las dos personas superpuestas en el pronombre de la primera persona plural, nos, destaca la presencia de esa alienación en su presente y con lo 
cual engloba, además, a los otros, a los consumidores de las mercancías; porque, como ellos, él es otro consumidor alienado, ofuscado por los medios empleados para la divulgación comercial, es decir, por medios tan violentos y desmesurados como los de la producción y el consumismo establecidos (la orgía publicitaria nos deslumbra tras esos lujosos matices...).

En suma, el yo se manifiesta en presente cuando pretende afirmar su integridad y ejercer sus facultades físicas, intelectuales, éticas y morales (palpo, conozco, habito, me rindo, denuncio); así, construye su escritura desde el presente. Se distancia del pasado pero se identifica con éste, porque la integración de las dos temporalidades afirma su identidad; quizás, por ello, el poemario se titula Cronista del presente.

\section{Una ciudad cualquiera: entre la sátira y el Apocalipsis}

El hablante se personaliza e indetermina a la ciudad agresora por medio de la superposición de la segunda y de la tercera personas en los posesivos (tus calles, tu ámbito, su tenaz arquitectura, sus pies) y, sobre todo, con el realce de la tercera persona en el artículo genérico una y con la calificación indefinida cualquiera (una ciudad cualquiera); de este modo, la convierte en estereotipo, digna de poca consideración.

La jungla, el pulpo y el laberinto son tres metáforas construidas por Brecht, Verhaeren y Butor, las cuales ponen de manifiesto una visión pesimista de la condición humana en la ciudad industrial, una realidad inhumana, monstruosa. Cada una de estas metáforas contiene, respectivamente, una forma de agresividad:

La jungle signifie le retour à la forêt primitive, c'est-à-dire la régression de la culture à la nature, de l'humanité à l'animalité, de la justice à la loi du plus fort, de l'ordre au chaos. Dans la jungle des villes, l'homme est un loup pour l'homme (...).

L'oeuvre de Verhaeren présente un autre aspect de la reálité urbaine: le fantasme de la pieuvre dévorant l'espace et les hommes, absorbant leur énergie vitale, enchaînant les corps humains aux rouages des machines, rend compte du caractère insatiable de la ville géante (...).

Le labyrinthe suggère quant à lui une agression de la ville plus insidieuse encore puisqu'elle menace l'homme au plus profond de son être: il traduit en effet le sentiment angoissant de perte, dans tous les sens du terme; perte des repères spatiuax, écroulement de l'univers familier, des cadres rassurants de l'existence, égarement dans l'inconnu et l'absurde ("ce qui est dénué de sens"), perte du sentiment de sa prope identité et, si l'on va jusqu'au terme du sens de ce mythe, menace d'anéantissement: le minotaure dévore ses victimes (Laffitte 1995: 17).

La ciudad textual, una ciudad cualquiera, transcodifica la ciudad laberinto; tipo que el hablante parodia, caricaturiza, a partir, precisamente, del verso número 9 , cifra que, como se anotó, resalta una transposición.

El poema se intertextualiza, entonces, con la célebre producción satírica de Juvenal, quien testimonia la decadencia del imperio y su cosmopolita capital, y denuncia "les turpides et les pestilences physiques et morales qui infectent Rome même, la gigantesque et cosmopolite capitale du monde antique (...)" (Fenaux 1995: 33).

La deambulación constituye un tópico simbólico y un recurso importante para el reconocimiento y la mostración de las grandes ciudades; tópico de raíces muy antiguas y que, por ejemplo, está presente en el Satiricón de Petronio, obra contemporánea de Nerón.

El hablante deambula por las calles de la ciudad y con este desplazamiento configura un rico universo de sensaciones, de percepciones y de impresiones; yuxtapone el presente 
y el pasado y puntualiza tanto el permanente y propio poder de agresión de la ciudad como la decadencia, la enfermedad, que esta padece: (Te palpo desde dentro, ciudad donde naciera. I Al deambular por la belleza doliente de las calles / con la urbana sumisión, me aniquilas. I Los exteriores municipales dan carácter a sus tinieblas industriales).

El yo, al deambular cotidianamente por las calles, palpa la hostilidad del espacio urbano: un espacio oscuro, en tinieblas, como consecuencia de la polución que lanzan las industrias. La actividad económica invade el ecosistema urbano y, por consiguiente, esfuma las relaciones solidarias entre las partes de un todo: el ambiente, desde la tierra hasta la biosfera, o sea, el lugar de lo viviente y lo no-viviente, de la transformación de la materia y de la energía.

La ciudad textual es, pues, un espacio de desechos, o sea, una perversidad del desarrollo urbano, lo cual se recalca con la actitud negligente de la municipalidad que, en vez de velar por los intereses de sus habitantes, otorga, con sus exteriores, rasgos específicos a la contaminación intensa. La actividad económica, que engrandece y sostiene a la ciudad, paradójicamente, la enferma, la contamina con su propia riqueza, con su propio dinero; no es casual, entonces, que este problema central, capital, aparezca en el verso número 5.

En el laberinto de la urbana sumisión, de aniquilación de la humanidad, el desarrollo económico establece una estructura socio-económica que se caracteriza por una compleja multiplicación de contradicciones sociales, es decir, la relación entre el capital y el trabajo determina la fisonomía de la ciudad. La implantación de nuevas fuentes o de industrias exige un gran consumo de mano de obra y arrastra la afluencia de autóctonos y de emigrados; sin embargo, como todo laberinto, la ciudad tiene su centro, o sea, un espacio interior organizado desde donde ejerce el poder. Así, la multitud, el proletariado popula y multiplica la riqueza; pero la plaza, el centro de las actividades comerciales, financieras y administrativas, es dominada por unos pocos, por la burguesía, que devora a sus víctimas, la multitud: En tu ámbito me hiciste / y forjaste mi trabajo como una mercancía sugestiva / de hijo local de una ambiciosa plaza que a golpes de riqueza se poblara.

Una ciudad cualquiera constituye, entonces, un centro de desigualdad social por la explotación; dr. segregación, ricos/pobres y autóctonos/emigrados y de atomización del cuerpo social por la presencia masiva y anónima, por la preeminencia de las relaciones contractuales, por la imposibilidad del contacto directo y personal con los otros, por la inevitable soledad moral, por la violencia exacerbada y por la desorganización.

La violencia intensa y la desorganización se explicitan, también en los ruidos (golpes de riqueza), en la invasión multicolor que ofusca la vista y obliga al pestañeo constante ( $L a$ orgía publicitaria nos deslumbra tras esos lujosos matices) y en la invasión y destrucción de la herencia cultural (su tenaz arquitectura, la belleza doliente de tus calles).

En su abundancia desmesurada, esta ciudad laberinto se convierte en víctima de su opulencia y de su agresividad; como estereotipo, como una réplica de sus congéneres, sufre también el síntoma de todas: un letargo, es decir, el síntoma de varias enfermedades nerviosas, infecciosas o tóxicas, caracterizado por un estado de somnolencia profunda y prolongada (Diccionario de la Lengua Española 1992: 1246), el cual mina progresivamente su vitalidad: (Es el letargo de una ciudad cualquiera / que conozco y que habito, huera y ruda, / mustia y nociva, protervamente renegada).

Esta saturación semántica de los adjetivos y del adverbio que complementa y refuerza el último adjetivo deviene en una saturación de epítetos, de caracterizaciones que recalcan la sátira, la parodia de la soberbia de una ciudad cualquiera. 
Al normalizar el conjunto semémico, o sea, al reunir los semas-núcleos, de conformidad con las orientaciones de la Real Academia, y los semas contextuales, el volumen textual no solo esclarece cómo es una ciudad cualquiera, sino también, por qué se encuentra en decadencia, es decir, con un

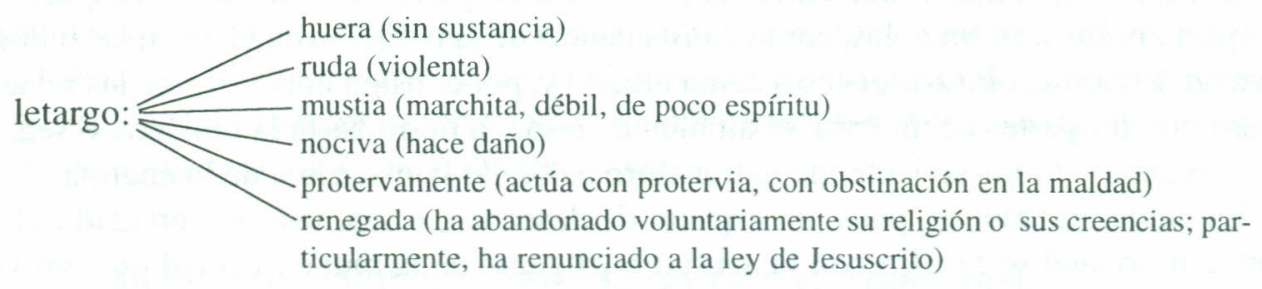

En suma, una ciudad cualquiera no posee sustancia, esencia; está marchita, débil y con poco espíritu. Hace daño y con obstinación corrompe las costumbres al renunciar a la ley de Jesucristo.

Así las cosas, la sátira focaliza la blasfemia de una ciudad cualquiera, que reniega su propia esencia divina y humana. Hecha a imagen y semejanza del ser humano es, por consiguiente, una consubstancialidad: materia y espíritu, pero la prepotencia de su materialismo le mina el espíritu, el ánimo; finalmente, el letargo se convierte en enfermedad y la soberbia ciudad deviene en una urbe crepuscular; se sumerge, entonces, en un estado de ánimo, intermedio entre la conciencia y la inconsciencia (Ibid: 594), es decir, en un estado en que ya no se reconoce en sus atributos esenciales y, por ello, no los puede reconocer en los otros.

Esta ciudad materializada y desligada de lo espiritual sólo puede actuar de manera irreflexiva, puesto que no puede reflejar su imagen humana en la de los otros, ni los otros se pueden reflejar en ella; esta irreflexión se connota en el propio título del poema: "Intrépida ciudad de provincia".

El hablante, en la medida en que parodia y revela la enfermedad de la urbe crepuscular, se devela, simultáneamente, como una conciencia receptora/emisora de lo "ya dicho": la ley de Jesucristo; al identificarse con ese "ya dicho", se identifica consigo mismo y con los demás.

Se proyecta, pues, en un comportamiento de referencia y se identifica con una imagen instituida y trasmitida por la conciencia colectiva: la consubstancialidad divina y humana, la cual crea, básicamente, la solidaridad de todos los hombres en Cristo y la supremacía del espíritu sobre la materia. La vida y doctrina de Jesús representan, simbólicamente, la victoria de la luz sobre las tinieblas, cuyo denso contenido se puede sintetizar en tres capítulos esenciales: la paternidad de Dios, que debe inspirar una confianza filial, el Reino de los Cielos, de carácter espiritual y universalista, y el amor al prójimo -el próximo-, ya sea el amigo o el enemigo (Pérez Rioja 1962: 124); fundamentos que una ciudad cualquiera desvirtúa, reniega.

El yo, al afirmarse en su humanidad, es decir, en su propia consubstancialidad material y espiritual, o en una categoría universal, pretende eliminar el emplazamiento de las relaciones de clase. Por ello, sin hablar, sin luchar, ya que le basta reconocerse en los demás, se rinde o se sujeta a los pies de la tenaz arquitectura, memoria de las generaciones, a los pies de los emigrados y a los pies de Bilbao: a su tenaz arquitectura, al tráfico hoy lleno de emigrados, me rindo taciturno / a sus pies y denuncio el ultraje de mi Bilbao explotador.

Los pies se asocian, simbólicamente, con el alma y con la tierra (Chevalier y Gheerbrant 1995: 749-51); el poema deconstruye ambos sentidos. En la polisemia textual, lo espiritual se 
manifiesta tanto en el quehacer humano (a su tenaz arquitectura) como en la naturaleza; esta última atribución se connota en pies, que es un signo del ser humano, de muchos animales, de las plantas y de los árboles, y en explotador, que es un signo de los minerales, de los metales y de las minas. El último verso integra los tres reinos, el animal, el vegetal y el mineral, es decir, la naturaleza de Bilbao como un símbolo de lo espiritual, de la abundancia y de lo intemporal, pero que esta misma ciudad explota y destruye; explotación que la vuelve mustia, marchita, o sea, en un símbolo de lo material, de la carencia y de lo temporal.

Bilbao está desarticulado, domina la parte sobre el todo, la capital sobre el resto. Esta desmembración aparece igualmente dispuesta en el poema: la cabeza (capital) en el título, y los pies, en el último verso; aunque, definitivamente, el último verso forma los dos vértices de la base que junto con capital integran un triángulo, es decir, la cabeza, los pies y Bilbao son tres manifestaciones especulares:

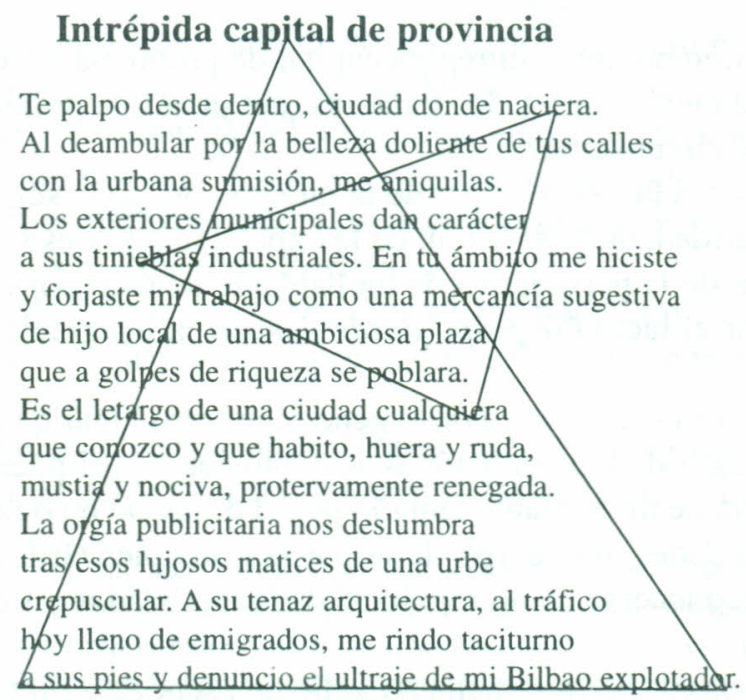

En consecuencia, el título y el último verso constituyen la circularidad estructural del poema. Esta circularidad se pone de relieve del siguiente modo: el título plantea el enigma ¿cuál es el nombre? o ¿quién es la intrépida capital de provincia?; luego, el conjunto de los versos, desde el primero hasta el decimoquinto, conforma la dilación que retarda la respuesta con el fin de construir una amplia caracterización de la capital como una ciudad cualquiera; finalmente, el último verso despeja el enigma, surge la respuesta y se revela el nombre de la capital, del referente, mi Bilbao explotador.

El hablante nombra al explotador, al culpable de su consubstancialidad repudiada, después de denunciar el ultraje (denuncio el ultraje de mi Bilbao explotador); pero el hablante ya había denunciado la explotación que ejerce Bilbao como el propio ajamiento que esta ciudad sufre, sentidos que ratifica con el témino ultraje. Así las cosas, ¿es el nombre del culpable, del Bilbao fratricida, lo que él denuncia para que reciba el castigo correspondiente?, ¿mas de cuál autoridad o tribunal? En el marco de lo "ya dicho", de la tradición judeocristiana que él reproduce, el tribunal no puede ser otro que el de la Santa Trinidad.

En lo "ya dicho", en el Génesis, subyace la fundación de la ciudad, donde coexisten la culpa y la expiación: 


\begin{abstract}
Toutes les villes avec leurs activités industrielles, textiles, leurs créations artistiques, renvoient à la descendance de Caïn. Caïn le maudit reçoit le signe du Seigneur qui le rend invulnérable et qui l'autorise en quelque sorte à construire le mur de briques. A l'origine de la ville, il y a la faute, mais Caïn est autorisé par le Seigneur à se racheter en créant les lieux de la sédentarité (...). La ville est en quelque sorte expiation, tentative de rachat, cependant elle garde la trace de la faute originelle (Barbet 1995: 114).
\end{abstract}

En el Apocalipsis, se encuentra la destrucción de toda ciudad soberbia, de la ciudad creada por el ser humano. En consecuencia, el hablante, al satirizar la soberbia de su Bilbao explotador, afirma los principios del discurso de la revelación: la victoria de los justos y la esperanza de la vida eterna.

\title{
5. Una ciudad cualquiera: una metáfora del yo
}

Pero si el nombre de la intrépida capital de provincia se revela, la madre y la patria o la nación, "lo no dicho", son las dos palabras que jamás se pronuncian; sin embargo, ambas quedan claramente circunscritas.

La madre es, a la vez, el lugar de la integración, de la seguridad, del abrigo, de la ternura y de la inseguridad, de la división, de la expulsión... por eso, en el poema, la imagen materna se percibe desde la perspectiva de un hablante tentado por el deseo de regresar al útero y de reconocer, por el tacto ( $T e$ palpo desde dentro) la integración, la seguridad y la ternura que no puede ver.

La patria, como la madre, por lo general, es otro lugar de integración, de afección, de seguridad y de inseguridad, de división o de expulsión. En el poema, la imagen patria se percibe desde el ángulo de un hablante tentado por el deseo de reconocer, por el tacto, la integración de las extremidades del cuerpo de la patria (¿los pies (Bilbao) y la capital o la cabeza (Madrid)?) para reconocerse como hijo local de la totalidad territorial (En tu ámbito me hiciste (...) / hijo local).

En ambos casos, el yo se halla en ardiente oscuridad, en tinieblas, sin reconocerse, lo "no dicho". Así, al parodiar la soberbia de una ciudad cualquiera, teatraliza su drama de identidad, la parodia de sí mismo, puesto que la ciudad laberinto es una metáfora de él mismo. Al asimilarse con la ciudad cualquiera por la comparación tácita en el posesivo mi Bilbao, activa otra vez la especularidad de las interrogantes contenidas en el primer triángulo, cuyos vértices poseen, también, el simbolismo de los números 1, 5, 9; interrogantes enmascaradas por el triángulo mayor, por la referencialidad, pero desenmascaradas por la intersección de los dos triángulos, por la connotación.

En suma, el hablante se revela en su propio laberinto: en tinieblas, como un cualquie$r a$, fragmentado y poseído por el fantasma de la integración -como lo manifiesta la propia organización del poema- y que, en consonancia, no puede abstraerse de emplear el pretérito imperfecto de subjuntivo naciera, precisamente, en el verso número $1 \ldots$

\section{El país vasco o la identidad fragmentada}

Puesto que Bilbao constituye una clave de decodificación de Intrépida capital de provincia, en tanto que representa un símbolo evocador del medio que constituye el foco de las 
preocupaciones del hablante, de su drama de identidad, se intenta indagar brevemente la compleja situación socioeconómica y sociopolítica del País Vasco, de Bilbao.

El País Vasco se encuentra dividido entre Francia y España, y es, en esta última, donde se localiza la mayor parte de su territorio.

Entre 1492 y 1833 esta región no presenta problemas con la corona, con el poder central. El problema emerge con la pérdida de los fueros, pero estalla como una oposición entre el particularismo vasco y el estado español con las guerras carlistas del siglo XIX (1833-1839 y 1872-1876). El poder central castiga a las provincias rebeldes y, en 1876, elimina definitivamente los fueros, lo cual crea entre los vascos un fuerte sentimiento en contra de Madrid.

A pesar de la divergencia de opiniones, se puede afirmar que la concentración de los yacimientos mineros juega un papel determinante en el desarrollo de Viscaya y, sobre todo, de Bilbao. A partir de 1850, se produce la industrialización de Viscaya, época en que sufre una transformación política y social, que se evidencia en el fuerte crecimiento demográfico provocado por la avalancha migratoria que conlleva la explotación de las minas. El desarrollo de ia industria siderúrgica permite, también, la creación de astilleros y de un vasto sector de industrias metalúrgicas. Como consecuencia del proceso de industrialización, se forma la zona metropolitana de Bilbao, centro del País Vasco en su conjunto, su núcleo financiero y económico, pero no cultural; es su capital económica, la más importante, pero no la única. En el plano administrativo, Bilbao es la capital de Viscaya.

La industrialización de Bilbao y su fuerte dinamismo traen graves problemas como la segregación de las actividades, la dispersión entre el domicilio y los puestos de trabajo, y la contaminación intensa del ambiente.

Bilbao es cuna y fortaleza de las reivindicaciones vascas nacionalistas; es una mezcla de generaciones, de ideologías y de pobladores procedentes de las diferentes partes de la península:

\footnotetext{
Depuis que Bilbao est devenu une zone industrielle, on a toujours vu dans cette ville des carlistes et des libéraux, des patriotes basques et des patriotes espagnols, des Unamuno et des Arana, des révolutionnaires et des ultras, autrement dit des chassés-croisés de sentiments nationaux en tous points opposés. Bilbao est le berceau et la forteresse des revendications nationalistes basques (...). De fait, Bilbao correspond au mélange et au croisement asymétrique du vieux Basque et de l'Espagnol récent, des idéologies progressistes comme conservatrices. Croisement et mélange de gens du pays - plus précisément de gens affluant de la Biscaye rurale - et de gens venus par vagues successives du fin fond de la péninsule (Azurmendi 1994: 92-3).
}

Desde sus orígenes, el País Vasco, cuya denominación es de por sí discutible, nunca se ha unificado ni se ha independizado. Por el contrario, ha fragmentado su identidad con el persistente sentimiento de una comunidad fundada en una lengua, aunque hoy sólo es hablada por una minoría urbana; con un ambiguo sentimiento anti Madrid pero no anti España; con un racismo aliado a un catolicismo intransigente; con la formación, en 1895, del Partido Nacionalista Vasco (PNV) y con los efectos de la profunda división, de la represión, de la persecusión y de los exilios a que lo sometió la Guerra Civil.

Entre 1950 y 1970, la represión y la prosperidad económica vasca, que cobra auge a partir de 1959, calman las pasiones políticas; pero, en el seno del país, surge una generación, que reprocha la inercia y el pacifismo de los líderes nacionalistas que envejecen en el exilio, y crea ETA. Fundada en 1959, esta nueva organización inicia sus acciones en 1962; poco después, se vuelve socialista y luego marxista-leninista... 
En síntesis, el sentido y el significado de "Intrépida capital de provincia" implican, pues, los contextos socioeconómico, sociopolítico y sociocultural del País Vasco y de Bilbao, su capital económica.

\section{Bibliografía}

Amoretti, María. 1992. Diccionario de términos asociados en teoría literaria. Costa Rica: Editorial de la Universidad de Costa Rica.

Azurmendi, José Félix. 1994. "Bilbao, au-delà de ses images”. En: Gabastou, André, 92-102.

Chevalier, Jean et Alain Gheerbrant. 1995. Dictionnaire des symboles. Paris: Éditions Robert Laffont/Jupiter.

Cros, Edmond. 1986. Literatura, ideología y sociedad. Madrid: Editorial Gredos.

Fenaux, Jean-Paul. 1995. "La poésie et la ville de Juvénal à Aragon”. En: Analyses \& réflexions sur Émile Verhaeren: Les Villes tentaculaires, 33-7.

Gabastou, André. 1994. Nations basques: Peuple mythique, aventure universelle. Paris: Éditions Autrement.

Ouvrage collectif. 1995. Analyses \& réflexions sur Bertolt: Dans la jungle des villes. Paris: Éditions Ellipses.

Ouvrage collectif. 1995. Analyses \& réflexions sur Émile Verhaeren: Les Villes tentaculaires. Paris: Librairie Vuibert Supérieur.

Pérez-Rioja, J.A. 1962. Diccionario de símbolos y de mitos. Madrid: Editorial Tecnos.

Racine, Jean-Bernard. 1993. La ville entre Dieu et les hommes. Paris: Diffusion Anthropos Económica.

Real Academia. 1992. Diccionario de la Lengua Española. Madrid: Editorial Espasa-Calpe.

Trías, Eugenio. 1984. Drama e identidad. España: Editorial Ariel. 